\title{
Study of Yeast POF Character Impact on Hop Flavor Expressions in Hoppy Beers
}

\author{
Gabriela G. Montandon, ${ }^{1}$ Philippe Janssens, ${ }^{1}$ Gert De Rouck, ${ }^{2}$ Filip Van Opstaele, ${ }^{2}$ \\ and Yves Gosselin ${ }^{1}$ \\ 1. Fermentis Research \& Development, Société Industrielle Lesaffre, Marcq en Baroeul, France \\ 2. KU Leuven, Faculty of Engineering Technology, Laboratory of Enzyme, Fermentation and Brewing Technology, Ghent Technology \\ Campus, Ghent, Belgium
}

\begin{abstract}
Yeasts may play a unique role in heavily hopped beers from different perspectives. To evaluate the impact of different yeast strains, two types of trials at pilot scale were performed: one with a New England IPA type beer and another with a brut IPA type beer. In both trials, POF+ yeast strains produced higher amounts of phenolic flavors, which were

perceived by the trained assessors. Along with it, a reduced overall intensity perception of the entire hop expression was noticed. The high dosage of fruity hops added in later stages in these IPA beer types is not enough to cover the perception of phenolic flavors, even when below the threshold level.
\end{abstract}

In the 150 years since Louis Pasteur published Études sur la Bière, brewers have acquired a much greater understanding of the diversity of brewer's yeasts, but little has been explored with regard to the interaction of yeast and raw materials such as hops. By thoughtfully choosing yeast strains, brewers can accentuate the fruity flavor profile found in heavily hopped beers with tropical and citrus aromas.

New and heavily hopped beer styles have emerged recently, such as the new members of the India pale ale (IPA) beer family. Examples of hazy IPAs (or New England IPAs) and brut IPAs have been quickly spread on beer shelves - and, although there is plenty of information about hop variety recommendations, little is known about the most appropriate yeast type to produce these kinds of beers. Yeasts may play a unique role in heavily hopped beers from different perspectives: (1) transforming and releasing bound hop components by biotransformation; (2) producing fermentative fruity aromas that support or act synergistically with the perception of hop fruity flavors; and (3) producing fermentative compounds that negatively affect the overall perception of hop flavors. In the midst of several yeast-derived flavor-active compounds, fruity acetate and ethyl esters may be crucial, but so too are other powerful flavor compounds with low flavor thresholds, such as sulfur and phenolic compounds.

An important aspect of beer yeast strains is their difference in phenolic off-flavor (POF) gene expression. Some yeast strains have a specific enzyme that decarboxylates phenolic acids present in beer wort, such as ferulic acid and cinnamic acid, producing flavor-active compounds such as 4-vinyl-guaiacol and 4-vinylphenol, respectively. These components produce clovey, spicy, woody, or medicinal-like flavors and, depending on the concentration, may add complexity in some ales but also can impact the perception of other flavors. Thus, this work aims mainly to eluci-

E-mail: g.montandon@fermentis.lesaffre.com

https://doi.org/10.1094/TQ-56-4-1011-01

(C) 2019 Master Brewers Association of the Americas date the impact of $\mathrm{POF}+$ yeast strains on the hop flavor expression in hoppy beers.

\section{Methodology}

To evaluate the impact of different yeast strains, two types of trials at pilot scale were performed: one with a New England IPA type beer and another with a brut IPA type beer (Table 1). In both trials, $4 \mathrm{hL}$ of each single batch of wort was divided into $50 \mathrm{~L}$ sterile cylindroconical tanks, and the only parameter changed was the yeast strain. All beers were pitched with active dry yeasts at $50 \mathrm{~g} / \mathrm{hL}$ and fermented at $23^{\circ} \mathrm{C}$. Fermentation performance (attenuation by Anton Paar), volatiles (GC-MS), and sensory analysis (by quantitative descriptive analysis with the average of 18 trained panelists) were performed.

\section{Discussion and Conclusion}

Fermentation performances and volatile profiles for all studied conditions are shown in Table 2.

As expected, the yeasts produced different ratios of important flavor components, which differed for each yeast strain as well as for the same yeast strain in the two beer matrices studied (New England and brut IPA: cases of SafAle S33, K97, Be256, S04, and US05).

In both trials, $\mathrm{POF}+$ yeast strains (HA-18, BE-134, and T58) produced higher amounts of phenolic flavors, which were perceived by the trained assessors (Figs. 1 and 2). Along with it, a "reduced" overall intensity perception of the entire hop expression was noticed.

In conclusion, the high dosage of fruity hops added in later stages in New England IPA and brut IPA beer types is not enough to cover the perception of phenolic flavors, even when below the threshold level $(0.3 \mathrm{ppm})$. In addition, it was perceived that fruity POF- yeasts such as SafAle S33, SO4, and K97 played a bigger role in the overall fruity perception of hopped beers.

The next steps of this work are to investigate which of the evaluated fermentation components are the most important for the overall fruity-hop flavor perception, as well as to evaluate 
the possible activity of the yeast to metabolize hop components by biotransformation and lastly to better understand the masking effects of phenolic flavors.
In addition, the fermentation flavoring components produced by the yeasts must not be underestimated in heavily hopped beers. Phenolic flavors may act as a masking effect in a hopped beer in

Table 1. Pilot-scale trials conducted

\begin{tabular}{|c|c|c|c|c|}
\hline Trial & Original gravity & Wort composition & Hops and hop regimes & Yeasts \\
\hline NE IPA & $16^{\circ} \mathrm{P}$ & $\begin{array}{l}\text { Pils malt }(80 \%) \text {, wheat malt }(10 \%) \text {, } \\
\text { and oats }(10 \%)\end{array}$ & $\begin{array}{l}\text { Hop varieties: Simcoe, Mosaic, and Citra } \\
\text { Hop additions: whirlpool, fermentation days } \\
2 \text { and } 4 \text {, and maturation } \\
\text { Total amount: } 1 \mathrm{~kg} / \mathrm{hL}\end{array}$ & $\begin{array}{l}\text { SafAle S33 } \\
\text { SafAle S04 } \\
\text { SafAle US05 } \\
\text { SafAle K97 } \\
\text { SafAle BE256 } \\
\text { SafAle BE134* } \\
\text { SafAle T58* } \\
\text { SafLager S189 } \\
\text { SafLager S23 }\end{array}$ \\
\hline Brut IPA & $13^{\circ} \mathrm{P}$ & $\begin{array}{l}\text { Pils malt }(85 \%) \text {, saccharose }(15 \%) \text {, } \\
\text { and amyloglucosidase }(50 \mathrm{~g} / \mathrm{hL})\end{array}$ & $\begin{array}{l}\text { Hop varieties: Cascade, Mosaic, and Citra } \\
\text { Hop additions: whirlpool } \\
\text { Total amount: } 700 \mathrm{~g} / \mathrm{hL}\end{array}$ & $\begin{array}{l}\text { SafAle BE256 } \\
\text { SafBrew HA18* } \\
\text { SafAle K97 } \\
\text { SafAle S04 } \\
\text { SafAle S33 } \\
\text { SafAle US05 }\end{array}$ \\
\hline
\end{tabular}

a Asterisk (*) indicates POF+ yeasts. NE = New England.

Table 2. Fermentation and volatile profiles of New England (NE) IPA and brut IPA beers with different beer yeast strains

\begin{tabular}{|c|c|c|c|c|c|c|c|c|c|c|c|c|c|c|c|c|c|c|c|c|}
\hline Yeast & TFT & Alc & ADF & Dia & 4-VG & $n-P$ & EA & IB & 2-MB & 3-MB & IBA & EB & IAA & EH & PAlc & EO & PAc & ED & S_Alc & S_Es \\
\hline \multicolumn{21}{|l|}{ Brut IPA } \\
\hline BE256 & 48 & 8.8 & 106.4 & 2.62 & 0 & 10.4 & 37.2 & 25.7 & 14.99 & 108.9 & 0.224 & 0.1272 & 3.678 & 0.31 & 22.6 & 0.3818 & 1.022 & 0.11161 & 182.6 & 43.1 \\
\hline *HA18 & 48 & 8.9 & 106.2 & 5.37 & 0.177 & 8.7 & 36.3 & 23.9 & 9.37 & 153.6 & 0.237 & 0.2047 & 2.31 & 0.685 & 19.6 & 0.4449 & 0.913 & 0.07971 & 215.2 & 41.2 \\
\hline K97 & 48 & 8.7 & 106.1 & 3.33 & 0 & 9.8 & 38.6 & 15.3 & 11.24 & 106.2 & 0.157 & 0.1458 & 2.782 & 0.314 & 21 & 0.4342 & 0.839 & 0.05519 & 163.5 & 43.3 \\
\hline S04 & 48 & 8.8 & 107.0 & 6.07 & 0 & 9.5 & 26.7 & 31.3 & 13.1 & 109.7 & 0.324 & 0.1394 & 3.682 & 0.302 & 21.2 & 0.4221 & 1.423 & 0.14801 & 184.8 & 33.1 \\
\hline S33 & 48 & 8.7 & 105.2 & 3.08 & 0 & 11.2 & 51.7 & 19.2 & 10.58 & 129.2 & 0.265 & 0.2579 & 3.791 & 0.797 & 21 & 0.6616 & 1.237 & 0.18596 & 191.2 & 58.9 \\
\hline US05 & 96 & 8.7 & 106.1 & 10.28 & 0 & 9.1 & 22.9 & 15.6 & 10.21 & 77.3 & 0.068 & 0.1864 & 0.886 & 0.388 & 19.5 & 0.6886 & 0.309 & 0.12234 & 131.7 & 25.5 \\
\hline \multicolumn{21}{|l|}{ NE IPA } \\
\hline S33 & 144 & 5.9 & 75.0 & 8.52 & 0.169 & 39.8 & 48.9 & 31.5 & 13.17 & 107.5 & 0.176 & 0.149 & 2.42 & 0.962 & 56.4 & 0.213 & 0.569 & 0.047 & 248.4 & 53.4 \\
\hline S04 & 144 & 6.6 & 84.6 & 85.7 & 0.165 & 37.1 & 57.5 & 43.6 & 16.21 & 132.7 & 0.191 & 0.156 & 2.52 & 1.159 & 61.1 & 0.296 & 0.584 & 0.065 & 290.7 & 62.5 \\
\hline US05 & 144 & 7.5 & 89.1 & 98.49 & 0.112 & 30.8 & 46.4 & 35.2 & 12.03 & 94.8 & 0.099 & 0.32 & 1.37 & 0.586 & 25.8 & 0.304 & 0.205 & 0.024 & 198.6 & 49.3 \\
\hline K97 & 144 & 7.4 & 89.6 & 14.57 & 0.147 & 28.7 & 59.1 & 30.9 & 17.14 & 130.9 & 0.081 & 0.192 & 2.32 & 1.327 & 56.1 & 0.304 & 0.442 & 0.049 & 263.7 & 63.8 \\
\hline BE256 & 144 & 7.6 & 90.0 & 13.39 & 0.131 & 24.6 & 56.1 & 53.4 & 20.13 & 143.4 & 0.227 & 0.158 & 3.41 & 0.638 & 65.1 & 0.262 & 0.807 & 0.071 & 306.6 & 61.7 \\
\hline *BE134 & 144 & 8.0 & 93.7 & 7.98 & 0.262 & 32.7 & 74.8 & 35.6 & 11.77 & 126.8 & 0.229 & 0.402 & 3.21 & 0.733 & 45.9 & 0.378 & 0.64 & 0.072 & 252.8 & 80.5 \\
\hline *T58 & 144 & 6.9 & 80.9 & 19.93 & 0.201 & 32.1 & 62.9 & 38.8 & 16.21 & 152.2 & 0.226 & 0.247 & 3.46 & 0.828 & 47.6 & 0.313 & 0.497 & 0.061 & 286.9 & 68.5 \\
\hline S189 & 144 & 7.6 & 88.2 & 15.3 & 0.118 & 13.8 & 49.9 & 18.0 & 10.4 & 113.2 & 0.073 & 0.135 & 1.48 & 0.566 & 35.8 & 0.246 & 0.367 & 0.028 & 191.2 & 52.8 \\
\hline $\mathrm{S} 23$ & 144 & 7.6 & 87.6 & 13.97 & 0.114 & 12.9 & 47.9 & 14.6 & 9.23 & 117 & 0.063 & 0.153 & 1.47 & 0.588 & 35.6 & 0.266 & 0.375 & 0.034 & 189.3 & 50.8 \\
\hline
\end{tabular}

a Asterisk (*) indicates POF+ strain. Column headings: TFT = total fermentation time $(\mathrm{h})$; Alc $=$ alcohol $(\mathrm{v} / \mathrm{v} \%)$; ADF $=$ apparent degree of fermentation $(\%)$; Dia $=$ diacetyl (ppb); 4-VG = 4-vinyl guaiacol (ppm); $n$-P = n-propanol (ppm); EA = ethyl acetate (ppm); IB = iso-butanol (ppm); 2-MB = 2-methyl-butanol (ppm); 3-MB = 3-methyl-butanol $(\mathrm{ppm}) ; \mathrm{IBA}=$ isobutyl acetate $(\mathrm{ppm}) ; \mathrm{EB}=$ ethyl butanoate $(\mathrm{ppm}) ; \mathrm{IAA}=$ isoamyl acetate $(\mathrm{ppm}) ; \mathrm{EH}=$ ethyl hexanoate $(\mathrm{ppm}) ; \mathrm{PAlc}=$ phenylethyl alcohol $(\mathrm{ppm}) ; \mathrm{EO}=\mathrm{ethyl}$ octanoate $(\mathrm{ppm}) ; \mathrm{PAc}=$ phenylethyl acetate $(\mathrm{ppm}) ; \mathrm{ED}=$ ethyl decanoate $(\mathrm{ppm}) ; \mathrm{S} \_\mathrm{Alc}=$ sum of alcohols $(\mathrm{ppm})$; and S_Est $=$ sum of esters $(\mathrm{ppm})$

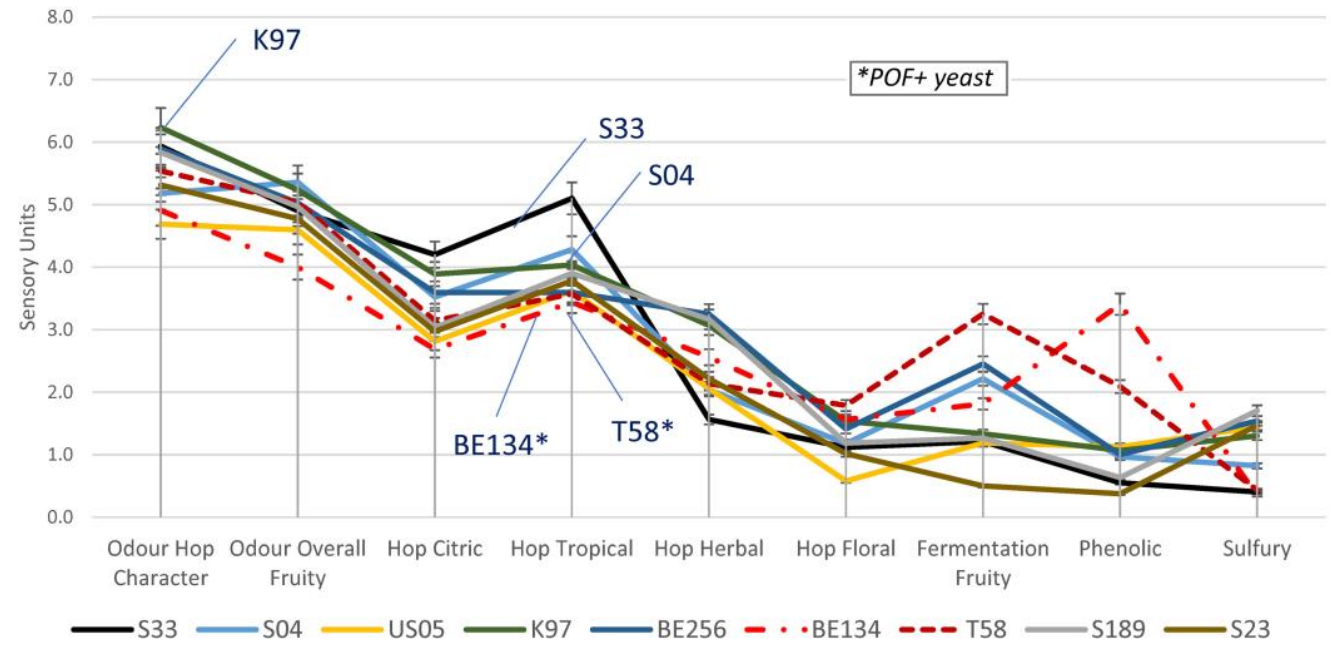

Figure 1. Sensory analysis of New England IPA. 


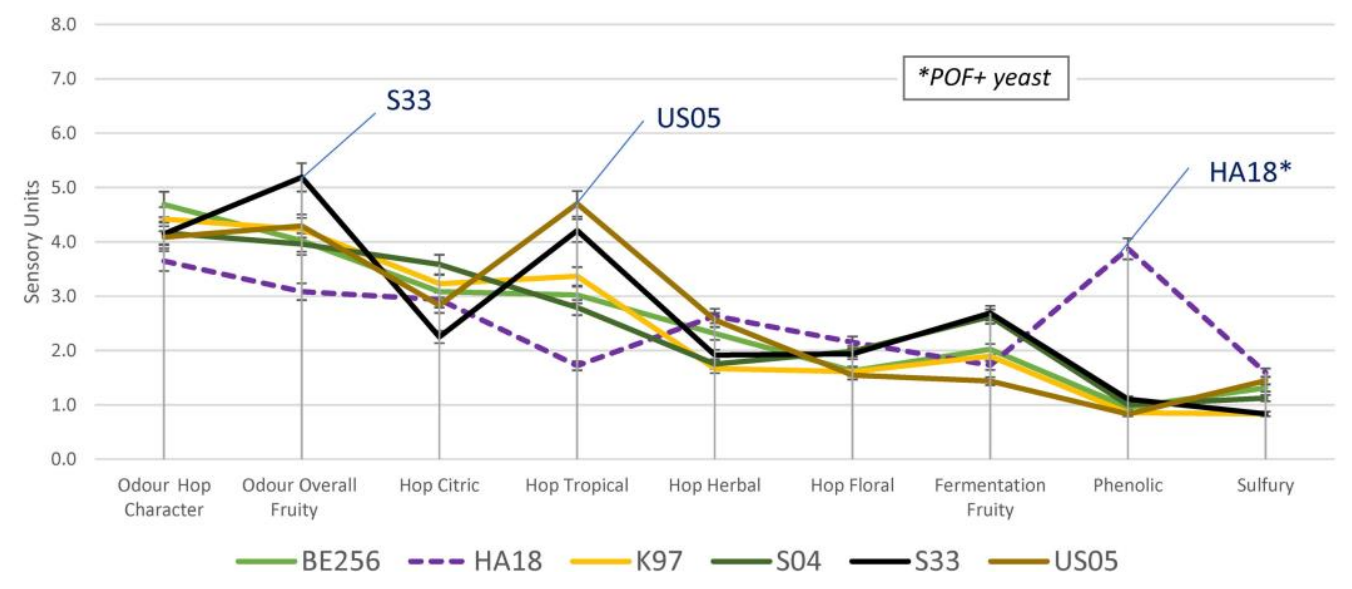

Figure 2. Sensory analysis of brut IPA.

which intense fruity flavors are expected, and in this scenario not necessarily neutral yeast strains must be the most appropriate choice for hoppy beer styles. The amount and/or variety of fruity compounds derived from fermentation as a consequence of the metabolism of a given yeast strain must be considered as an elementary factor for overall fruity flavors in hopped beer. 